\title{
True Choice in Reproductive Care: Using Cultural Humility and Explanatory Models to Support Reproductive Justice in Primary Care
}

\author{
Megha Shankar, $M D^{1,2}$ (D) Meagan Williams, $M D^{3}$, and Adelaide Hearst McClintock, MD ${ }^{3}$
}

'VA Palo Alto Health Care System Center for Innovation to Implementation (Ci2i), Menlo Park, CA, USA; ${ }^{2}$ Stanford University Center for Primary Care and Outcomes Research (PCOR) and Center for Health Policy (CHP), Stanford, CA, USA; ${ }^{3}$ Department of Medicine, Division of General Internal Medicine, University of Washington, Seattle, WA, USA.

Reproductive justice is the human right to maintain personal bodily autonomy, have children, not have children, and to parent children in safe and sustainable communities. Historically, marginalized individuals have experienced reproductive oppression in multiple forms. This oppression continues in modern times through health policy and patient-clinician communication. To combat this, the framework of reproductive justice outlines four key actions: analyzing power systems, addressing intersecting oppressions, centering the most marginalized, and joining together across issues and identities. Primary care clinicians have a unique role and responsibility to carry out these four key actions in order to provide patient centered reproductive care. To translate reproductive justice into clinical practice, clinicians care can use reflective practice, the framework of cultural humility, and the concepts from the explanatory model of illness.

J Gen Intern Med 36(5):1395-9

DOI: $10.1007 / \mathrm{s} 11606-020-06245-8$

(c) Society of General Internal Medicine (This is a U.S. government work and not under copyright protection in the U.S.; foreign copyright protection may apply) 2020

\section{INTRODUCTION}

Reproductive justice is the human right to maintain personal bodily autonomy, have children, not have children, and to parent children in safe and sustainable communities. ${ }^{1}$ This term emerged from Black feminist scholars in response to the women's rights movement, which was largely led by affluent, white women and did not adequately advocate for those marginalized. Today, it is a multi-cultural movement to highlight the critical role of access to reproductive care, calling attention to the fact that without access to information or options there is no "choice." In addition to services like contraception or abortion,

Prior presentations: This manuscript is based on a workshop entitled "Highly effective, respectful, and culturally informed reproductive counseling: overcoming a legacy of racism" which was submitted by all authors of this manuscript and accepted for presentation at National SGIM 2020, canceled due to COVID-19.

Received June 2, 2020

Accepted September 11, 2020

Published online September 24, 2020 reproductive justice highlights access to sex education, sexually transmitted infection prevention and treatment, preconception care, and prenatal care. The reproductive justice framework addresses the intersecting structural barriers to reproductive health, such as intimate partner violence, opportunity gaps, and financial and structural confinement unsafe for individuals.

For individuals marginalized by their identities, associations, experiences, and environment, ${ }^{2}$ reproductive justice has been denied by our medical system. From enslavement to modern day, there are policies and practices that demonstrate devaluing lives of marginalized populations, such as medical experimentation on Black bodies without consent, forced sterilization of Indigenous people or those who are (dis) abled or incarcerated, and policies that prevent women who receive government assistance from having more children. ${ }^{3,4}$ Patients of color regularly encounter racism in accessing family planning services, ${ }^{5,6}$ and clinicians are more likely to recommend limiting family size and the use of long-acting reversible contraceptive (LARC) methods for patients of color or perceived lower socioeconomic status. ${ }^{7}$ These patterns of behavior in medicine are evidence of the devaluing of marginalized lives in favor of a white majority.

To achieve reproductive justice, four key actions have been identified: analyze power systems (identifying and eradicating macro and micro forms of dominance), address intersecting oppressions, center the most marginalized, and join together across issues and identities. ${ }^{1}$ In addressing these four key actions in the context of primary care, clinicians must recognize how power is denied and restore it to marginalized individuals. Engagement in reflective practice on clinician identities can highlight how clinicians' own values may bias patient care. By truly partnering with patients in their reproductive health, clinicians can center care around patients' identities, lived experiences, and values.

We propose that the framework of cultural humility ${ }^{8}$ and the concepts behind Arthur Kleinman's explanatory model of illness ${ }^{9}$ can be used to promote reproductive justice in primary care. In this paper, we outline these concepts for patientcentered communication as they relate to reproductive justice. We use clinical cases to illustrate common scenarios in primary care where access to sex education, pregnancy care, or parenting support have historically been withheld or limited, 
and offer suggestions for identifying and re-centering care around patient-stated values. Creating shared language and mental models of reproductive health with each patient can help illuminate barriers to accessing desired services and give clinicians patient-defined tools to disrupt reproductive oppression.

\section{FRAMEWORKS FOR REPRODUCTIVE JUSTICE IN PRIMARY CARE}

Primary care clinicians are often the first point of contact with the health system. Attention has been given to the role primary care clinicians play in reproductive counseling, ${ }^{10}$ with recommendations to address this at least yearly. ${ }^{11}$ Layering the historical context and disparities of marginalized people, there are barriers to patient trust when providing reproductive counseling.
Some tools already exist for patient-centered discussions about reproductive intentions in the primary care setting. One Key Question ${ }^{12}$ (OKQ) and PATH Questions ${ }^{13}$ (Table 1) are open-ended questions to understand patient intentions and avoid assumptions. OKQ (Would you like to become pregnant in the next year?) is a way for clinicians to ask patients about pregnancy. However, the question is phrased for a yes/no answer and includes a 1-year timeframe which may not be meaningful to patients, ${ }^{14}$ as up to one in four US reproductive age women feels ambivalent about pregnancy. ${ }^{15}$ The PATH questions seek to understand patients' reproductive goals by asking about their parenthood/pregnancy attitude, timing, and prevention. While the open-ended nature of the PATH questions aligns with patient-centered approaches, ${ }^{14}$ these questions are limited in their ability to foster understanding of an individual's baseline knowledge, or to examine the larger social or cultural contexts and intersecting forms of oppression.

Table 1 Patient-Centered Reproductive Health Frameworks

\begin{tabular}{|c|c|c|c|c|}
\hline \multicolumn{2}{|c|}{$\overline{\text { Explanatory } \text { Model }^{9}}$} & \multirow{2}{*}{$\begin{array}{l}\text { One Key } \\
\text { Question }^{\circledR}{ }^{12}\end{array}$} & \multirow[t]{2}{*}{ PATH Questions*13 } & \multirow[t]{2}{*}{ Additional questions } \\
\hline Concepts & Questions & & & \\
\hline Shared language & $\begin{array}{l}\text { What do you call your problem? } \\
\text { What name does it have? }\end{array}$ & & & $\begin{array}{l}\text { What questions do have about } \\
\text { fertility, pregnancy, or sexual } \\
\text { activity and reproductive health? }\end{array}$ \\
\hline Etiology & $\begin{array}{l}\text { What do you think has caused } \\
\text { your problem? }\end{array}$ & & & $\begin{array}{l}\text { Is there anyone you would like to } \\
\text { include or exclude from this } \\
\text { discussion? }\end{array}$ \\
\hline Timing & $\begin{array}{l}\text { Why do you think it started when } \\
\text { it did? }\end{array}$ & $\begin{array}{l}\text { Would you like to } \\
\text { become pregnant in } \\
\text { the next year? }\end{array}$ & $\begin{array}{l}\text { Timing if desiring future } \\
\text { pregnancy- When do you } \\
\text { think that you might like to } \\
\text { have (more) children? }\end{array}$ & $\begin{array}{l}\text { How important is it to you to be } \\
\text { able to plan or time (spacing } \\
\text { between) your pregnancies? } \\
\text { Is there anyone in your life who is } \\
\text { trying to influence your decisions } \\
\text { about (sexual activity, pregnancy } \\
\text { or contraception)? }\end{array}$ \\
\hline Pathophysiology & $\begin{array}{l}\text { What do you think the sickness } \\
\text { does? How does it work? }\end{array}$ & & & $\begin{array}{l}\text { What questions do you have about } \\
\text { how contraceptive methods work } \\
\text { or what they do in your body? } \\
\text { What is your understanding of } \\
\text { how your medical issues might } \\
\text { impact pregnancy (or } \\
\text { contraceptive choice)? }\end{array}$ \\
\hline Severity/course & $\begin{array}{l}\text { How severe is it? Will it have a } \\
\text { long or a short course? }\end{array}$ & & & $\begin{array}{l}\text { What impact would a pregnancy } \\
\text { now have for you? }\end{array}$ \\
\hline Fears & $\begin{array}{l}\text { What do you fear most about } \\
\text { your sickness? }\end{array}$ & & & $\begin{array}{l}\text { What fears or concerns do you } \\
\text { have about contraception, } \\
\text { pregnancy, or parenting? }\end{array}$ \\
\hline Feelings/ideas & $\begin{array}{l}\text { What are the chief problems the } \\
\text { sickness has caused for you? }\end{array}$ & & $\begin{array}{l}\text { Parenthood/pregnancy } \\
\text { Attitude - Do you think you } \\
\text { might like to have (more) } \\
\text { children at some point? }\end{array}$ & \\
\hline $\begin{array}{l}\text { Treatment/ } \\
\text { expectations }\end{array}$ & $\begin{array}{l}\text { What kind of treatment do you } \\
\text { think you should receive? What } \\
\text { are the most important results } \\
\text { you hope to receive from the } \\
\text { treatment? }\end{array}$ & & & $\begin{array}{l}\text { What is the most important thing } \\
\text { you want your contraceptive } \\
\text { method to do for you? } \\
\text { What do you hope for your } \\
\text { pregnancy (or for when you are a } \\
\text { parent)? }\end{array}$ \\
\hline
\end{tabular}

*Note that PATH questions are intended to be asked in order of "Pregnancy Attitudes, Timing and 'How important'" but are presented out of order here to highlight the concepts of the explanatory model that each falls into 
For further exploration of patient values, cultural humility and the explanatory model can be applied as an extension of the above frameworks to develop a deeper understanding of patients' perspectives. The concept of cultural humility is maintaining "an interpersonal stance that is other-oriented (or open to the other) in relation to aspects of cultural identity" that an individual prioritizes. ${ }^{16}$ Clinicians can apply cultural humility to promote the four actions of reproductive justice by identifying reproductive values with the goal of fostering autonomy and demonstrating respect for patients. Cultural humility maintains the patient as the expert in their health, prioritizing the patient's own explanation of their health in shared decision making.

The explanatory model seeks to bring the patient's voice to the forefront with eight questions that explore patients' feeling, ideas, fears and expectations regarding the five domains of illness: etiology, timing, pathophysiology, course of sickness, and treatment (Table 1). ${ }^{17}$ While the explanatory model was developed for cross cultural communication about disease, these domains can be applied to preventive and reproductive health. Each patient's own explanatory model influences their openness to preventive and treatment-seeking health behaviors ${ }^{18}$ and is crucial for clinicians to juxtapose with their own explanatory model of a patient's health. With this approach, clinicians can assess reproductive values, matching other aspects of primary care (medication choices, for example) and ensuring access to services that work towards reproductive justice.

\section{REFLECTIVE CASES}

Below are clinical scenarios applying the four tenets of reproductive justice. We offer reflection questions for clinicians to analyze power systems, considerations to acknowledge intersecting oppressions, and approaches to center the most marginalized and join together across issues and identities.

\section{7-Year-Old Black Woman Who Experiences Homelessness and Takes Lisinopril for Well- Controlled Hypertension Is Considering but Uncertain About Becoming Pregnant}

Refection Questions. What do you tend to think of people who are experiencing homelessness? What personal beliefs do you have about when and where children should be parented? What information are you assuming this woman has about her medical conditions or her medications? Can you relate to her ambivalence or is it uncomfortable for you not to have a "yes" or "no" answer?

Considerations. The history of reproductive coercion of Black bodies in the $\mathrm{USA}^{5}$ lays a foundation for power dynamics in this interaction and highlights the intersecting oppressions of race and homelessness. Clinicians may have personal beliefs about when and where children should optimally be parented, which may not align with the circumstances of patients' lives or values. Given the use of a teratogenic medication and housing instability, a clinician may open a conversation about pregnancy planning with, "What are you using for contraception?" inadvertently implying that the clinician may not believe pregnancy to be acceptable. Some may also feel compelled to "help her resolve" her ambivalence, but this may also be experienced as coercive or dismissive of her values.

Approaches to Reproductive Justice. Routinely asking patients on teratogenic medications OKQ (at the time of initial prescription and refill) can open the door to a discussion about pregnancy intention, and align care to her goals, potentially switching the medication, for example. ${ }^{19}$ Alternatively, using the explanatory model to understand what kind of treatment she wants to receive for her blood pressure, and what results she hopes for, may identify that she wants a medication that would be safe in pregnancy as well as in the context of her housing status. Clinicians may ask, "What do you hope for your pregnancy or for when you are a parent?" (Table 1) to elicit paths to partner with her in pregnancy and support her in parenting, ambivalence, and reproductive values.

\section{1-Year-Old Indigenous Woman with Cognitive Impairment Is in a Stable Relationship and Interested in Preventing Pregnancy Now but Wants Children in the Future}

Reflection Questions. What are your beliefs about the capabilities of people with cognitive impairment? How might these beliefs impact your approach to reproductive counseling? What information do you assume she might have about sexual activity, pregnancy, or contraception?

Considerations. Historical practices routinely excluded individuals with (dis) abilities from parenthood and denied autonomy over their reproductive lives. ${ }^{3}$ Today, people with (dis) abilities are routinely left out of basic sexual education ${ }^{20}$ and report difficulty in finding clinicians who understand the interplay between (dis) ability and reproductive health. ${ }^{21}$ Biases regularly encountered by patients with (dis) abilities and implied in this exclusion are the beliefs that individuals with (dis) abilities are not sexually active, are not entitled to a safe and healthy sex-life, and are not able to parent. ${ }^{22}$ Given documented high rates of sexual abuse in women with disabilities, ${ }^{23}$ clinicians should also consider whether there are people trying to influence patients' decisions about sexual activity, pregnancy, or contraception. 
Approaches to Reproductive Justice. Clinicians can open the door to this discussion with a question to define common language and assess patient understanding by asking, "What questions do you have about fertility, pregnancy, or sexual activity and reproductive health?" (Table 1) or using PATH questions to assess attitudes and orientation towards pregnancy. Given disparities around sexual abuse and coercive power dynamics, ${ }^{24}$ this may also be an opportunity to ask, "Is there anyone you would like to include or exclude from this discussion?" (Table 1) when exploring her decisions about sexual activity, pregnancy, or contraception. If she desires contraception, clinicians can ask what is important to her about her method $^{25}$ to develop a lasting, trusting relationship and ensuring they will continue to care for this patient through contraception and preconception when she feels ready.

\section{2-Year-Old Latinx Transman with Uterus and Ovaries Present and Not on Hormone Therapy Wants to Become a Parent in the Next Year}

Reflection Questions. What is your existing knowledge base for providing reproductive counseling to trans* people? What assumptions might you make around trans* people and desire for pregnancy? How might you offer routine preventive healthcare to patients with a trauma-informed approach?

Considerations. Trans* people have the same range of reproductive intentions and desires as non-trans* individuals. Assuming that male gender identity precludes a desire for pregnancy is a missed opportunity to understand and align with a patient's care goals. Trans* people may avoid healthcare facilities due to history of trauma as well as clinicians' lack of understanding of their health concerns. ${ }^{26}$ Trans* people report the need for more supportive resources and to educate their clinicians on their reproductive health. ${ }^{26,27}$

Approaches to Reproductive Justice. Asking about his pregnancy intentions using $\mathrm{OKQ}{ }^{\circledR}$ or the PATH questions is one way to open a non-judgmental dialog, hear him discuss preferred reproductive terms, and build a trusting relationship. ${ }^{28}$ Individuals should be counseled about fertility preservation prior to pubertal suppression or treatment with gender affirming hormones. ${ }^{29}$ Clinicians can ask "What impact would a pregnancy now have for you?" to learn about the patient's reproductive values in the context of his identity. Using the explanatory model concepts to understand patient hopes, fears, and concerns about pregnancy, clinicians may learn that this patient is fearful of pregnancy exacerbating his gender dysphoria. ${ }^{30}$ Clinicians can support this patient in his desire for parenthood by ensuring routine preconception care and counseling, along with providing appropriate resources to address his fears. Combining trauma informed care in the context of gender dysphoria along with principles of cultural humility, clinicians can join with this patient across issues and identities to empower him in his health.

\section{CONCLUSION}

Primary care clinicians have a critical role as partners in assembling the foundation for patients' reproductive values and supporting patients' freedom to decide if, when, and how often to have children, and where and how to parent them. Clinicians have a responsibility to identify and examine their own assumptions, values, and biases, and actively work to provide patient-centered reproductive counseling that supports the human right to reproductive justice. Cultural humility and the explanatory model offer an extended framework for centering patient values, experiences, expectations, and goals. In doing so, clinicians hold the opportunity and honor of empowering all patients in their health.

Corresponding Author: Megha Shankar, MD; VA Palo Alto Health Care System Center for Innovation to Implementation (Ci2i), Menlo Park, CA, USA (e-mail: meghs@stanford.edu).

Funding MS is supported by a VA Office of Academic Affairs Advanced Fellowship in Health Services Research. The views expressed herein are those of the authors and do not necessarily reflect the views of the Department of Veterans Affairs.

\section{Compliance with Ethical Standards:}

Conflict of Interest: The authors declare that they do not have a conflict of interest.

\section{REFERENCES}

1. Reproductive Justice. Accessed January 2, 2020. https://www. sistersong.net/reproductive-justice

2. Hall JM, Stevens PE, Meleis AI. Marginalization: a guiding concept for valuing diversity in nursing knowledge development. ANS Adv Nurs Sci 1994;16(4):23-41. https://doi.org/10.1097/00012272-19940600000005

3. Patel P. Forced sterilization of women as discrimination. Public Health Rev 2017;38(1): 15. https://doi.org/10.1186/s40985-017-0060-9

4. Romero D, Agénor M. US fertility prevention as poverty prevention: an empirical question and social justice issue. Womens Health Issues 2009;19(6):355-364. https://doi.org/10.1016/j.whi.2009.08.004

5. Prather C, Fuller TR, Jeffries WL, et al. Racism, African American Women, and their sexual and reproductive health: a review of historical and contemporary evidence and implications for health equity. Health Equity 2018;2(1):249-259. https://doi.org/10.1089/heq.2017.0045

6. Callegari LS, Tartaglione EV, Magnusson SL, et al. Understanding women veterans' family planning counseling experiences and preferences to inform patient-centered care. Womens Health Issues 2019;29(3):283289. https://doi.org/10.1016/j.whi.2019.03.002

7. Dehlendorf $\mathbf{C}$, Ruskin $\mathbf{R}$, Grumbach $\mathbf{K}$, et al. Recommendations for intrauterine contraception: a randomized trial of the effects of patients' race/ethnicity and socioeconomic status. Am J Obstet Gynecol. 2010;203(4):319.e1-8. https://doi.org/10.1016/j.ajog.2010.05.009

8. Tervalon M, Murray-Garcia J. Cultural humility versus cultural competence: a critical distinction in defining physician training outcomes in multicultural education. J Health Care Poor Underserved 1998;9(2):117125. https://doi.org/10.1353/hpu.2010.0233 
9. Kleinman A. Patients and Healers in the Context of Culture: An Exploration of the Borderland Between Anthropology, Medicine, and Psychiatry. 8. [print]. University of California Press; 2003.

10. Borrero S, Callegari L. Integrating family planning into primary care-a call to action. J Gen Intern Med 2020;35(3):625-627. https://doi.org/ 10. 1007/s11606-019-05576-5

11. Ian. Clinical Preventive Services for Women. Institute of Medicine. Published online July 2011. Accessed Jul 27, 2020. https://www.nap. edu/resource/13181/reportbrief.pdf

12. One Key Question Support 2020 | Power to Decide. Accessed Jun 30, 2020. https://powertodecide.org/one-key-question

13. Envision SRH PATH Questions Examples. Accessed Jun 30, 2020. https://www.envisionsrh.com/path-questions-examples

14. Callegari L, Aiken A, Dehlendorf C, Cason P, Borrero S. Addressing potential pitfalls of reproductive life planning with patient-centered counseling. Am J Obstet Gynecol. 216. https://doi.org/10.1016/j.ajog. 2016.10.004

15. McQuillan J, Greil AL, Shreffler KM. Pregnancy intentions among women who do not try: focusing on women who are okay either way Matern Child Health J 2011;15(2):178-187. https://doi.org/10.1007/ s10995-010-0604-9

16. Hook JN, Davis DE, Owen J, Worthington EL, Utsey SO. Cultural humility: measuring openness to culturally diverse clients. J Couns Psychol 2013;60(3):353-366. https://doi.org/10.1037/a0032595

17. Buchbinder M. THE CANON - 5. Patients and healers in the context of culture: an exploration of the borderland between anthropology, medicine, and psychiatry, by Arthur Kleinman. Anthropol Med 2013;20(1):109-111. https://doi.org/10.1080/13648470.2012.762337

18. Tirodkar MA, Baker DW, Makoul GT, Khurana N, Paracha MW, Kandula NR. Explanatory models of health and disease among South Asian immigrants in Chicago. J Immigr Minor Health 2011;13(2):385394. https://doi.org/10.1007/s10903-009-9304-1

19. Santucci AK, Gold MA, Akers AY, Borrero S, Schwarz EB. Women's perspectives on counseling about risks for medication-induced birth defects. Birth Defects Res A Clin Mol Teratol 2010;88(1):64-69. https:// doi.org/10.1002/bdra.20618

20. Kallianes V, Rubenfeld P. Disabled women and reproductive rights. Disabil Soc 1997;12(2):203-222. https://doi.org/10.1080/ 09687599727335
21. Mosher W, Hughes RB, Bloom T, Horton L, Mojtabai R, Alhusen JL. Contraceptive use by disability status: new national estimates from the National Survey of Family Growth. Contraception. 97(6):552-558. https://doi.org/10.1016/j.contraception.2018.03.031

22. Iezzoni LI, Mitra M. Transcending the counter-normative: sexual and reproductive health and persons with disability. Disabil Health J 2017;10(3):369-370. https://doi.org/10.1016/j.dhjo.2017.04.001

23. Basile KC, Breiding MJ, Smith SG. Disability and risk of recent sexual violence in the United States. Am J Public Health 2016;106(5):928-933. https://doi.org/10.2105/AJPH.2015.303004

24. French Jr. JRP, Raven B. The bases of social power. In: Studies in Social Power. Univer. Michigan; 1959:150-167.

25. Whetstone $\mathbf{S}$. Quality Contraception Care: Counseling and Controversies. Presented at the: 2019. https://www.ucsfcme.com/2020/ MDM20M05/slides/06_WHETSTONE_Quality_Contraceptive_Care.pd. Accessed 2 Jan 2020

26. Moseson H, Zazanis N, Goldberg E, et al. The imperative for transgender and gender nonbinary inclusion: beyond women's health. Obstet Gynecol 2020;135(5):1059-1068. https://doi.org/10.1097/AOG. 0000000000003816

27. Houssayni S, Nilsen $\mathbf{K}$. Transgender competent provider: identifying transgender health needs, health disparities, and health coverage. Kans J Med 2018;11(1):15-19.

28. Hashemi L, Weinreb J, Weimer AK, Weiss RL. Transgender care in the primary care setting: a review of guidelines and literature. Fed Pract 2018;35(7):30-37.

29. Morong JJ, Hinz E. Fertility preservation in transgender and gender non-conforming adults [21A]. Obstet Gynecol 2020;135:14S. https://doi org/10.1097/01.AOG.0000663036.53219.43

30. Obedin-Maliver $\mathbf{J}$, Makadon HJ. Transgender men and pregnancy. Obstet Med 2016;9(1):4-8. https://doi.org/10.1177/ $1753495 \times 15612658$

Publisher's Note: Springer Nature remains neutral with regard to jurisdictional claims in published maps and institutional affiliations. 